\title{
Is IGSF1 involved in human pituitary tumor formation?
}

\author{
Fabio R Faucz ${ }^{1,2,{ }^{*} \text {, Anelia D Horvath }}{ }^{1,{ }^{*}}$, Monalisa F Azevedo ${ }^{1, *}$, Isaac Levy', Beata Bak ${ }^{3}$, \\ Ying Wang ${ }^{3}$, Paraskevi Xekouki', Eva Szarek', Evgenia Gourgari ${ }^{1,4}$, Allison D Manning', \\ Rodrigo Bertollo de Alexandre ${ }^{1,2}$, Emmanouil Saloustros', Giampaolo Trivellin', \\ Maya Lodish', Paul Hofman ${ }^{5}$, Yvonne C Anderson ${ }^{5,6}$, Ian Holdaway ${ }^{7}$, Edward Oldfield ${ }^{8}$, \\ Prashant Chittiboina ${ }^{9}$, Maria Nesterova', Nienke R Biermasz ${ }^{10}$, Jan M Wit", \\ Daniel J Bernard ${ }^{3}$ and Constantine A Stratakis ${ }^{1,4}$
}

Correspondence should be addressed to C A Stratakis Email stratakc@mail.nih.gov

\begin{abstract}
IGSF1 is a membrane glycoprotein highly expressed in the anterior pituitary. Pathogenic mutations in the IGSF1 gene (on Xq26.2) are associated with X-linked central hypothyroidism and testicular enlargement in males. In this study, we tested the hypothesis that IGSF1 is involved in the development of pituitary tumors, especially those that produce growth hormone (GH). IGSF1 was sequenced in 21 patients with gigantism or acromegaly and 92 healthy individuals. Expression studies with a candidate pathogenic IGSF1 variant were carried out in transfected cells and immunohistochemistry for IGSF1 was performed in the sections of $\mathrm{GH}$-producing adenomas, familial somatomammotroph hyperplasia, and in normal pituitary. We identified the sequence variant p.N604T, which in silico analysis suggested could affect IGSF1 function, in two male patients and one female with somatomammotroph hyperplasia from the same family. Of 60 female controls, two carried the same variant and seven were heterozygous for other variants. Immunohistochemistry showed increased IGSF1 staining in the GH-producing tumor from the patient with the IGSF1 p.N604T variant compared with a GH-producing adenoma from a patient negative for any IGSF1 variants and with normal control pituitary tissue. The IGSF1 gene appears polymorphic in the general population. A potentially pathogenic variant identified in the germline of three patients with gigantism from the same family (segregating with the disease) was also detected in two healthy female controls.
\end{abstract}

http://erc.endocrinology-journals.org DOI: 10.1530/ERC-14-0465
(C) 2015 Society for Endocrinology Printed in Great Britain
Published by Bioscientifica Ltd 
Variations in IGSF1 expression in pituitary tissue in patients with or without IGSF1 germline mutations point to the need for further studies of IGSF1 action in pituitary adenoma formation.

\section{Introduction}

Gigantism, a rare condition that causes abnormal growth in children, often has a genetic etiology. Indeed, cases running in a family were first reported in the late nineteenth century (de Herder 2012). Growth hormone (GH)-secreting pituitary adenoma and/or hyperplasia are the main causes of gigantism in childhood. These lesions are much more common in adults and have an annual incidence of $\sim 3 / 1000000$ and a prevalence of about 60/1 000000 (Ezzat et al. 2004).

IGSF1 is a plasma membrane glycoprotein encoded by the 'Ig superfamily, member 1' (IGSF1) gene, located on Xq26.2. This gene is conserved in mammals and is expressed with transcripts of different lengths in many tissues, including muscle, heart, brain, testis, and pancreas (Frattini et al. 1998). A previous study by Sun et al. (2012) demonstrated that IGSF1 is highly expressed in the Rathke's pouch and the adult anterior pituitary in humans. IGSF1 deficiency has been linked to congenital central hypothyroidism (CCH), hypoprolactinemia, delayed puberty, testicular enlargement, increased body weight, and GH deficiency (Sun et al. 2012, Joustra et al. 2013, Nakamura et al. 2013, Tajima et al. 2013), which is mainly observed in males, as expected from an X-linked genetic defect. In Igsf1-knockout mice, a decrease in pituitary and circulating thyroid-stimulating hormone (TSH) was observed, most probably secondary to impaired thyrotropin-releasing hormone (TRH) receptor expression and signaling (Sun et al. 2012).

Based on the recent work from Sun et al. (2012), we have investigated IGSF1 germline variations in patients with gigantism and/or familial acromegaly from the NIH data registry and in healthy controls. We also tested the expression of IGSF1 in GH-producing adenomas. Although our data do not prove a definitive link between pituitary tumor formation and IGSF1, the variation in its pituitary expression and the high number of polymorphisms suggests that IGSF1 should be studied further as a possible modifier of somatomammotropinoma formation and/or their clinical expression.

\section{Materials and methods}

\section{Subjects \& protocol}

The IGSF1 gene was screened for germline mutations in 21 patients (seven females and 14 males; one female and two males from the same family) with gigantism or acromegaly and in 92 previously described controls (100\% white Americans, 60 females, and 32 males) with a negative family history of endocrine disorders (Horvath et al. 2009). All patients were previously reported (Stratakis et al. 2010, Glasker et al. 2011). Gigantism or acromegaly were diagnosed based on established criteria (Cook et al. 2004): high IGF1 levels according to age and sex and serum GH concentration $>1 \mathrm{ng} / \mathrm{ml}$ after a 2 -h $75 \mathrm{~g}$ oral glucose tolerance test in an appropriate clinical context, and pituitary macro- $(>10 \mathrm{~mm})$ or micro- $(<10 \mathrm{~mm})$ adenomas or pituitary hyperplasia in magnetic resonance imaging (MRI) imaging. Leukocyte DNA was isolated from each patient. Written informed consent was obtained from all participants and the study was approved by the Institutional Review Boards of the participating institutions.

\section{IGSF1 sequencing analysis}

DNA was extracted from peripheral blood leucocytes according to manufacturer's protocols (Qiagen). For all patients and controls, the complete IGSF1-coding and flanking intronic sequence was analyzed, as described previously (Faucz et al. 2011) using the primers and conditions described in Supplementary Table 1 (see section on supplementary data given at the end of this article).

\section{In silico analyses}

The Sorting Intolerant from Tolerant (SIFT) (http://sift.bii. a-star.edu.sg/), the Align-GVGD (Grantham Variation Grantham Deviation) (http://agvgd.iarc.fr/), and PolyPhen-2 (Polymorphism Phenotyping v2) (http://genetics. bwh.harvard.edu/pph2/) software packages were used to predict the pathogenic potential of the identified missense variants in IGSF1.

Published by Bioscientifica Ltd. 


\section{Cell cultures}

GH3 cells (rat somatomammotroph pituitary cell line) were maintained in Dulbecco's modified Eagle's medium (DMEM) supplemented with high glucose $(4500 \mathrm{mg} / \mathrm{l})$, $10 \%$ fetal bovine serum (FBS), penicillin (100 IU $/ \mathrm{ml})$, and streptomycin $(100 \mathrm{mg} / \mathrm{ml})$ in a humidified atmosphere at $37^{\circ} \mathrm{C}$ with $5 \% \mathrm{CO}_{2}$. HEK293 cells were cultured as described previously (Sun et al. 2012).

\section{Transfection and ELISA}

The p.N604T (c.1811A > C, rs146462069, NM_00117 0961.1) IGSF1 mutation was introduced by overlapping PCR in a pCMV6 IGSF1 gene open-reading frame plasmid (ORIGENE, Rockville, MD, USA; cat\#209621) or by site-directed mutagenesis as described in Sun et al. (2012). Approximately, $1 \times 10^{5} \mathrm{GH} 3$ cells were plated per well in 12 -well cluster dishes overnight $\left(37^{\circ} \mathrm{C}\right)$, washed, and replenished with Opti-MEM. GH3 cell lines were transiently transfected by electroporation using the Basic Nucleofector Kit for Primary Mammalian Endothelial Cells (Lanza, Basel, Switzerland; cat\#VCA-1001) following the manufacturer's protocol. The cells were transfected with plasmid DNA (6 $\mu \mathrm{g})$, expressing either the WT or the variant form of IGSF1 and harvested $48 \mathrm{~h}$ after the transfection. The supernatant from GH3 transfected cells was analyzed for GH expression levels using the rat/mouse GH ELISA Kit (cat\# EZRMGH-45K; Millipore, St Charles, MO, USA) following the manufacturer's instructions.

\section{Pulse-chase analysis (metabolic labeling)}

Metabolic labeling studies were performed as described by Rejon et al. (2013). Briefly, $1 \times 10^{6}$ HEK293 cells were seeded in $35 \mathrm{~mm}$ dishes and transiently transfected the following day with $2 \mu \mathrm{g}$ HA-tagged WT or p.N604T variant IGSF1 expression vector using Lipofectamine 2000 (Invitrogen), following the manufacturer's instructions. The cells were cultured in methionine and cysteine-free DMEM (supplemented with $4 \mathrm{mM}$ glutamine) for $3 \mathrm{~h}$ at $37^{\circ} \mathrm{C}$. The culture medium was then additionally supplemented with $198 \mu \mathrm{Ci}\left[{ }^{35} \mathrm{~S}\right]$ methionine $/\left[{ }^{35} \mathrm{~S}\right]$ cysteine (per $\mathrm{ml}$ ) for $15 \mathrm{~min}$. The cells were washed twice with warm PBS and then incubated in DMEM/10\% FBS supplemented with $2 \mathrm{mM}$ methionine, $2 \mathrm{mM}$ cysteine, and $4 \mathrm{mM}$ glutamine. Following 2, 4, 8, or $24 \mathrm{~h}$ at $37^{\circ} \mathrm{C}$ cells were lysed for $15 \mathrm{~min}$, on ice, in $200 \mu \mathrm{l}$ lysis buffer (PBS with $0.5 \%$ deoxycholate, 1\% Triton X-100, 10 mM EDTA (pH 8.0), $1 \mathrm{mM}$ phenylmethylsulfonyl fluoride, and Complete Mini
Protease Inhibitor Cocktail tablets, Roche). At the various time points cells were lysed after 15 min incubation with $\left[{ }^{35} \mathrm{~S}\right]$ methionine $/\left[{ }^{35} \mathrm{~S}\right]$ cysteine. Protein extracts were centrifuged for $15 \mathrm{~min}$ at $16000 \boldsymbol{g}$ to remove insoluble material. Ten microliter of supernatant was saved to assess the effectiveness of the labeling ('total') and the remaining immunoprecipitate (IP) with EZ-view Red anti-HA affinity gel, according to the instructions of the manufacturer (Sigma). The gel-bound proteins were eluted by adding $16 \mu$ of $2 \times$ loading buffer containing $\beta$-mercaptoethanol and boiling for $5 \mathrm{~min}$ at $95^{\circ} \mathrm{C}$ minimum. The proteins were resolved by SDS-PAGE (8\% Tris-Glycine) and visualized by autoradiography.

\section{Membrane trafficking analyses}

Membrane transport of WT and p.N604T variant forms of IGSF1 was assessed by immunofluorescence or cell-surface biotinylation of transiently transfected HEK293 cells, as described previously (Nakamura et al. 2013, Sun etal. 2012).

\section{Immunohistochemistry}

Human pituitary tissue used for immunostaining was obtained during surgery, formalin-fixed, and paraffinembedded, and sections $(5 \mu \mathrm{m})$ were mounted onto 3-aminopropyl-triethoxylasine coated slides (Sigma Chemical, Co.). Routine staining with hematoxylin and eosin (H\&E, Histoserv, Inc, Germantown, MD, USA) was performed on several sections across each sample. Unstained slides were used for immunostaining. The procedure is outlined as follows: the sections were deparaffinized with Histoclear (National Diagnostics, Atlanta, GA, USA) and rehydrated with a graded series of ethanol (absolute, 95, 70, and 50\% ethanol and distilled water), followed by antigen retrieval, which was performed by boiling the tissue sections in the Antigen Unmasking Solution ( $\mathrm{pH}$ 6; Vector Laboratories, Burlingame, CA, USA) for $20 \mathrm{~min}$ in a pressure cooker; the sections were then allowed to cool to room temperature (20 $\mathrm{min})$. The sections were immunostained using the antibody against IGSF1 (rabbit anti-human diluted 1:1000, Abcam ab66509, Cambridge, MA, USA). Immunostaining was identified by colorimetric staining using the ImmPRESS Polymer Detection Kit (Rabbit; Vector Laboratories) and counterstained with hematoxylin. Briefly, once sections had cooled to room temperature following antigen retrieval, sections were blocked in $0.3 \%(\mathrm{v} / \mathrm{v}) \mathrm{H}_{2} \mathrm{O}_{2}$ (Sigma) made in methanol for $30 \mathrm{~min}$. After a wash with Tris-buffered Saline (TBS, pH 7.4; diluted

Published by Bioscientifica Ltd. 
to $1 \times$ from a $10 \times$ stock, Quality Biologicals, Inc., Gaithesburg, MD) containing 0.01\% Tween 20 (Life Technologies) (TBS-T; $1 \times 15 \mathrm{~min}$ ) sections were blocked for $1 \mathrm{~h}$ at room temperature using 2.5\% normal horse serum (provided with the ImmPRESS Polymer Detection Kit). The tissue sections were then incubated with primary antibody made in blocking serum, in a humidified chamber overnight at $4{ }^{\circ} \mathrm{C}$. They were subsequently washed with TBS-T $(3 \times 5 \mathrm{~min})$ and incubated for $30 \mathrm{~min}$ at room temperature with the ImmPRESS reagent, followed by another washing step in TBS-T $(3 \times 5 \mathrm{~min})$. They were incubated with counterstain ImmPACT DAB peroxidase substrate (Vector Laboratories), as per manufacturer's instructions. The sections were then counterstained with Mayer's hematoxylin, mounted, and coverslips applied with VectaMount AQ Aqueous Mounting Medium (Vector Laboratories), or mounted without counterstaining.

\section{Homology model}

Homology models of the 6th Ig loop in IGSF1 with Asn or Thr at position 604 were generated using Phyre2 (http:// www.sbg.bio.ic.ac.uk/phyre2/) and Quark (http://zhanglab. ccmb.med.umich.edu/QUARK/). Figures of the resulting models were generated using PyMol (http://pymol.org/).

\section{Statistical analyses}

Data are described as frequencies and percentages, mean \pm standard deviation or median (inter-quartile range), as appropriate, and were analyzed using SAS v9.1 (SAS, Inc, Cary, NC, USA). All experiments were repeated at least three times. Categorical data were compared using the Fisher's exact test. A $P$ value $\leq 0.05$ was considered to be statistically significant.

\section{Results}

We identified a nonsynonymous genetic IGSF1 variant (p.N604T, c.1811A > C, rs146462069) in two males and one female (from the same family - a mother and two sons) (Glasker et al. 2011). All three patients showed evidence of central hypothyroidism; however, they had either pituitary somatomammotroph tumors and/or hyperplasia or were seen in our hospital after they had their first operation. Eighteen additional unrelated patients were negative for the variant. All patients have been described previously (Stratakis et al. 2010, Glasker et al. 2011). The minor allele frequency of this variant is 0.01 (http://www. 1000genomes.org/). In silico analysis predicted this variant as possibly damaging. Of the 60 healthy female controls, two carried this variant and seven carried various other nonsynonymous variants (one nonsense, one frameshift, and six missense, Table 1). The variant was not seen in any of the 32 healthy males studied.

To investigate whether the p.N604T variant could be related to gigantism in our patients, we examined its impact on IGSF1 protein function. Transfection of GH3 cells with the p.N604T IGSF1 variant did not significantly affect $\mathrm{GH}$ production compared with cells transfected with WT IGSF1 ( $P=0.1561$, data not shown). Metabolic studies showed that both the WT and mutant proteins exhibit the same pattern of maturation and stability when expressed in heterologous cells (see Supplementary Figure 1, see section

Table 1 Variants found in 92 healthy controls

\begin{tabular}{|c|c|c|c|c|c|}
\hline $\begin{array}{l}\text { Chrom X } \\
\text { position } \\
\text { (in hg19) }\end{array}$ & DNA change $^{a}$ & Protein change & Exon & SNP id & Domains \\
\hline $130,420,579$ & c. $70 \mathrm{C}>\mathrm{T}$ & p.R24W & 2 & COSM1465661 & $\begin{array}{l}\text { Signal } \\
\text { peptide }\end{array}$ \\
\hline $130,419,882$ & c. $238 A>G$ & p.180V & 4 & Novel & NTD \\
\hline $130,419,793$ & c. $327 \mathrm{G}>\mathrm{T}$ & p.W109C & 4 & Novel & NTD \\
\hline $130,417,192$ & c. $714 \mathrm{G}>\mathrm{A}$ & p.M238I & 6 & Novel & NTD \\
\hline $130,412,680$ & C. $1811 \mathrm{~A}>\mathrm{C}$ & p.N604T & 12 & rs146462069 & CTD \\
\hline $130,412,680$ & C. $1811 \mathrm{~A}>\mathrm{C}$ & p.N604T & 12 & rs146462069 & CTD \\
\hline $130,412,078$ & c.2091dupC & p.Thr698Hisfs*24 & 13 & Novel & CTD \\
\hline $130,412,018$ & c. $2147 \mathrm{G}>\mathrm{A}$ & p.G716E & 13 & Novel & CTD \\
\hline $130,408,107$ & c.3844delC & p.V1282X & 19 & Novel & CTD \\
\hline
\end{tabular}

\begin{tabular}{|c|c|c|}
\hline \multicolumn{3}{|c|}{ In silico modeling prediction } \\
\hline SIFT & Polyphen & Align-GVGD \\
\hline Tolerated & Benign & $\begin{array}{l}\text { Probably } \\
\text { damaging }\end{array}$ \\
\hline Tolerated & Benign & Benign \\
\hline Tolerated & $\begin{array}{l}\text { Probably } \\
\text { damaging }\end{array}$ & $\begin{array}{l}\text { Probably } \\
\text { damaging }\end{array}$ \\
\hline Tolerated & Benign & Benign \\
\hline Tolerated & $\begin{array}{l}\text { Probably } \\
\text { damaging }\end{array}$ & $\begin{array}{l}\text { Possibly } \\
\text { damaging }\end{array}$ \\
\hline Tolerated & $\begin{array}{l}\text { Probably } \\
\text { damaging }\end{array}$ & $\begin{array}{l}\text { Possibly } \\
\text { damaging }\end{array}$ \\
\hline Tolerated & Benign & $\begin{array}{l}\text { Probably } \\
\text { damaging }\end{array}$ \\
\hline
\end{tabular}

CTD, c-terminal domain; GVGD, grantham variation/grantham deviation; NDT, n-terminal domain ${ }^{a}$ All DNA changes were found in females in heterozygosity.

http://erc.endocrinology-journals.org DOI: 10.1530/ERC-14-0465
(C) 2015 Society for Endocrinology Printed in Great Britain
Published by Bioscientifica Ltd. 
A
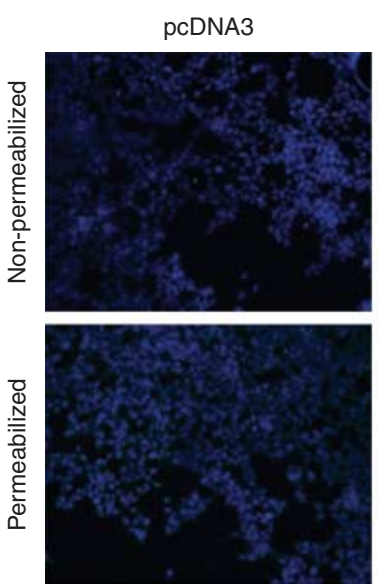
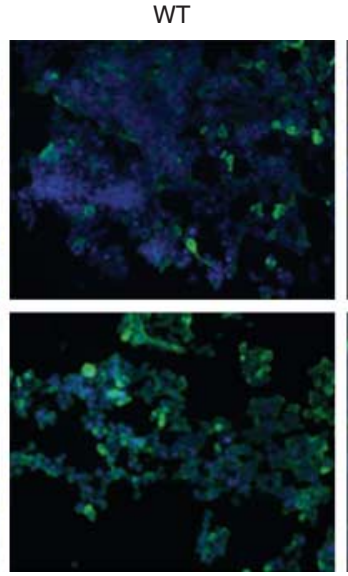
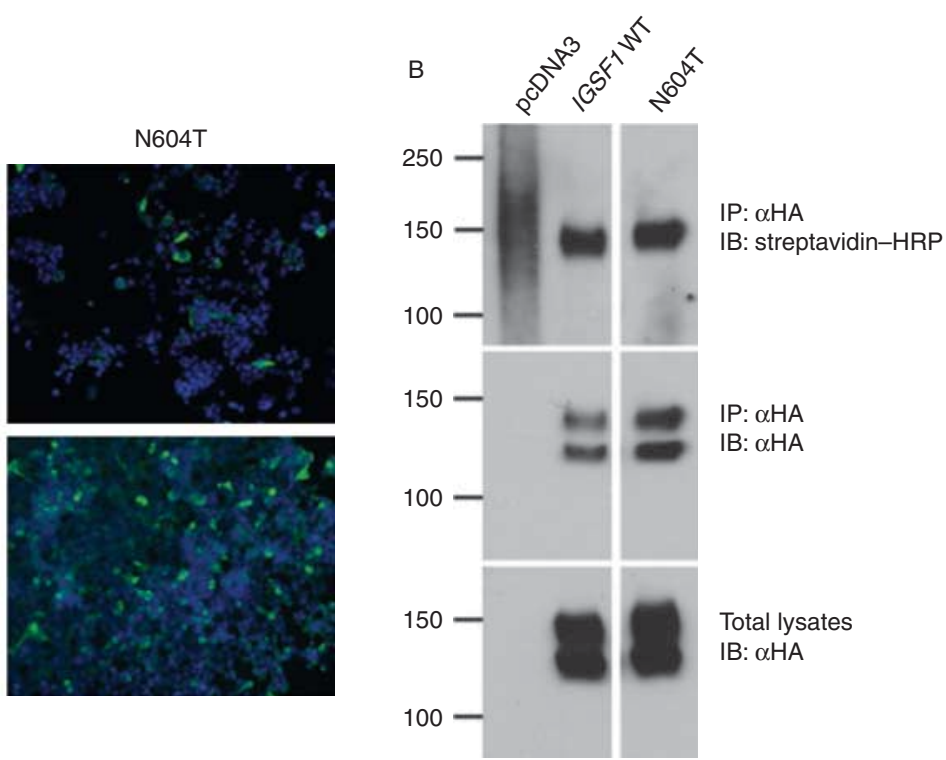

\section{Figure 1}

IGSF1 p.N604T traffics to the plasma membrane. (A) HEK293 cells were transfected with pCDNA3, IGSF1 WT, or IGSF1 p.N604T constructs and subjected to immunofluorescence under permeabilizing (bottom panels) and non-permeabilizing conditions (top panels). The proteins were detected with an antibody that recognizes the N-terminus of the IGSF1 CTD. (B) HEK293 cells were transfected with the indicated constructs and subjected to cell surface biotinylation followed by immunoprecipitation.

on supplementary data given at the end of this article). Both proteins were detected in the plasma membrane by immunofluorescence (Figure 1A) or cell surface biotinylation (Fig. 1B). By western blotting analysis, the WT and p.N604T proteins were indistinguishable (Fig. 1B, lower panels, lanes 2 and 3 ).

Asn604 maps to Ig loop 6 (of a total of 12) in the IGSF1 protein. IGSF1 is co-translationally cleaved into $\mathrm{N}$-terminal domains (NTD) and C-terminal domains (CTD) respectively). Ig loop 6 is at the $\mathrm{N}$-terminus of the CTD. We generated a homology model of Ig loop 6 and mapped Asn604 to a solvent-exposed surface (Fig. 2). Although no IGSF1 interacting partners have yet been identified, it is possible that the Asn $604 \mathrm{Thr}$ substitution could affect a protein-protein interaction surface.

Finally, immunohistochemical analysis of our patient's pituitary tumors carrying the IGSF1 variant showed increased IGSF1 staining compared with normal pituitary control or a GH-producing adenoma from a patient without the IGSF1 variant (Fig. 3). Three additional GH-producing adenomas from patients with acromegaly and no IGSF1 variants showed a similar pattern to that of the tumor shown in Figure 3 (data not shown).
Streptavidin-HRP signals of equal intensity were detected in cell lysates from WT and p.N604T transfected cells (top panel). The middle panel shows equivalent IP of the two proteins, whereas the bottom panel shows equivalent expression of the two proteins. Note that IGSF1 migrates as a double band on SDS-PAGE. The lower band corresponds to the core (immature) glycoform, whereas the upper band is the mature glycoform.

\section{Discussion}

We identified a hemizygous/heterozygous IGSF1 variant (p.N604T) segregating with gigantism in three patients in a family. Mutations in this gene were recently linked with CCH both in humans and mice (Sun et al. 2012, Nakamura et al. 2013, Tajima et al. 2013), perhaps secondary to loss of

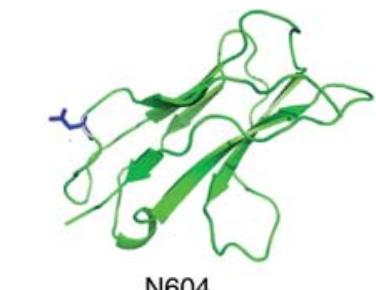

N604

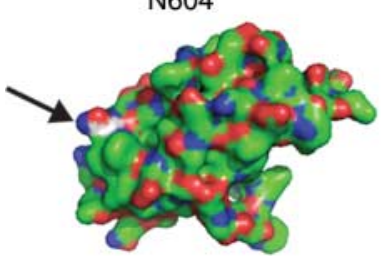

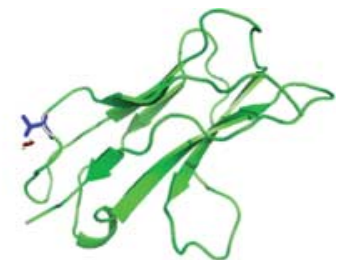

T604

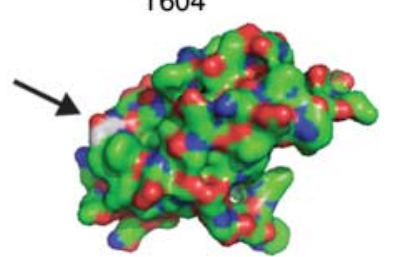

Figure 2

3D homology model of the IGSF1 Ig loop 6 in which the variant p.N604T resides. The arrows show the position of Asn (N) 604 and Thr (T) 604.

Published by Bioscientifica Ltd. 

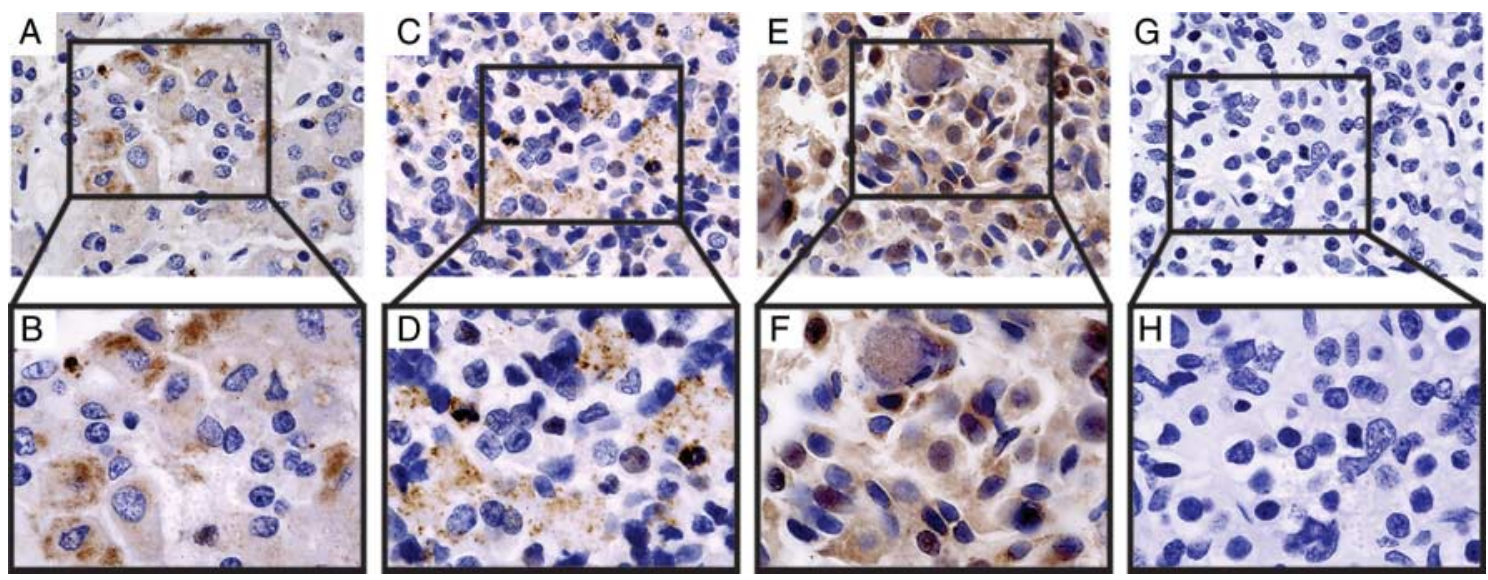

Figure 3

Immunohistochemistry of IGSF1 in normal pituitary and in GH-producing pituitary adenomas with and without p.N604T IGSF1 sequencing variant. (A/B) Normal Pituitary; (C/D) Patient with a GH-producing adenoma

TRH receptor expression and signaling in the pituitary (Sun et al. 2012). Considering its involvement in pituitary function and particularly in abnormal TSH secretion, as well as its demonstrated expression in murine somatotrope cells, we examined whether IGSF1 plays a causative role in our cohort of patients with gigantism or early-onset acromegaly.

Sequencing analysis of our 21 patients revealed an IGSF1-sequencing variant that we also observed in two female heterozygous controls. To date, 14 pathogenic mutations have been described in the IGSF1 gene (Sun et al. 2012, Nakamura et al. 2013, Tajima et al. 2013), all impair either protein maturation or membrane trafficking. Among these mutations, two are complete gene deletions and the remaining 12 are located in the extracellular portion of the CTD, an indication that this may represent an important functional domain of the protein.

Eight different variants (one nonsense, one frameshift, and six missense) were identified in our control group; all in females. We would expect that if the nonsense and frameshift mutations were carried by males, they might lead to some IGSF1 deficiency phenotypes, as $\mathrm{CCH}$ and several of the other clinical features of IGSF1 deficiency syndrome. Among the missense variants, two (p.W109C and p.N604T) were predicted as damaging by two programs and the remaining four (p.R24W, p.I80V, p.M238I and p.G716E) were predicted as benign by at least two programs. At a minimum, these observations reveal considerable polymorphism in this gene, including variants that could impair protein function.

A difference in the expression of IGSF1 in human pituitary was also noted; IGSF1 was intensely expressed without IGSF1 sequencing variants; (E/F) Patient with pituitary hyperplasia with the p.N604T IGSF1 variant; $(\mathrm{G} / \mathrm{H})$ negative control.

in the tumor from one of the hemizygous (male) patients carrying the IGSF1 variant compared with patients with GH-producing adenomas without an IGSF1 variant or with a normal pituitary tissue. However, we did not observe differences in GH secretion from GH3 cells engineered to express the p.N604T variant versus WT IGSF1, indicating that the variant is not sufficient to directly affect GH production and secretion.

Previously described pathogenic IGSF1 mutations affect the maturation and plasma membrane trafficking of the protein's CTD. However, we failed to detect any effect of the p.N604T IGSF1 variant on protein expression, maturation, stability, or membrane trafficking in heterologous cells. Therefore, if this variant alters IGSF1 function, it is likely through its extracellular activities. Given the prediction that the modified residue is solvent exposed and modifies the surface charge in the $6^{\text {th }}$ Ig loop (N-terminus of the CTD), it is tempting to speculate that the variant might alter IGSF1's interaction with an extracellular partner. However, this possibility must await the identification of extracellular ligands for the protein.

Although the sequence variant detected in our patients does not appear to affect GH levels, it may be acting as a modifier in $\mathrm{GH}$ and prolactin production and secretion. This is supported by the observation that the same variant was also found in a Finnish family with apparent X-linked delayed puberty, the index male case showing tall stature $(197 \mathrm{~cm})$ and hyperprolactinemia with normal brain MRI (Joustra et al. 2014).

In conclusion, the IGSF1 gene is polymorphic in the general population. The variant identified in three of our

Published by Bioscientifica Ltd 
patients with gigantism was also detected in apparently healthy female controls. It is also possible that the variantbearing allele is in linkage disequilibrium with the actual genetic cause of the phenotype in our family (Trivellin et al. 2014). Indeed, the apparent increase in pituitary IGSF1 expression in patients with an IGSF1 germline variant may indicate that IGSF1, while not playing a causative role in pituitary tumor development, could act synergistically in tumor development. Note that following the acceptance of this paper, our laboratory identified the genetic defect cosegregating with one of the described IGSF1 variants (c.1811A > C) (Trivellin et al. 2014). As this paper indicates, we believe that the phenotype of the family carrying the defect identified by Trivellin et al. (2014) and first described by Glasker et al. (2011) is indeed modified by this potentially functional IGSF1 variant.

\section{Supplementary data}

This is linked to the online version of the paper at http://dx.doi.org/10.1530/ ERC-14-0465.

\section{Declaration of interest}

The authors declare that there is no conflict of interest that could be perceived as prejudicing the impartiality of the research reported.

\section{Funding}

This study was supported by the Intramural Research Program, Eunice Kennedy Shriver National Institute of Child Health \& Human Development (NICHD), National Institutes of Health (NIH) (to C A Stratakis). Additional support was provided from a post-doctoral fellowship grant from CNPq and from the University of Brasilia, Brazil (to MFAzevedo; mentor: Dr C A Stratakis), in part, by a grant from the Conselho Nacional de Desenvolvimento Científico e Tecnológico (CNPq), Process: 311166/2011-3 - PQ-2 (to Fabio Rueda Faucz), and in part by a grant from Government of Canada-Canadian Institutes of Health Research, grant number CIHR MOP-133557 (to D J Bernard).

\section{Author contribution statement}

The contribution of each author is as follows: F R Faucz performed the in silico analyses, some of the molecular experiments described in the manuscript, and prepared the manuscript. A D Horvath and M F Azevedo, A D Manning, R B de Alexandre and G Trivellin performed most of the molecular experiments. I Levy and E Saloustros were involved in immunohistochemical studies. $B$ Bak and $Y$ Wang performed in vitro analyses of the IGSF1 variant. $P$ Xekouki and E Szarek participated in manuscript preparation and editing; E Gourgari, M Lodish, P Hofman, Y C Anderson, I Holdaway, and N R Biermasz were the clinicians involved in clinical analysis, patients' caring, and samples collection. E Oldfield was the physician who took care of the described kindred at the NIH. P Chittiboina was involved in pathology evaluation. $\mathrm{M}$ Nesterova prepared the clinical specimens for genetic analysis. J M Wit was involved in the interpretation of the data and in revising the various draft versions of the manuscript. D J Bernard directed the in vitro investigations of the IGSF1 variant, generated the homology model, and contributed to the writing of the

http://erc.endocrinology-journals.org DOI: 10.1530/ERC-14-0465
(C) 2015 Society for Endocrinology Printed in Great Britain manuscript. C A Stratakis was the senior investigator at NICHD, which provided most of the funding for this project under the NIH Intramural Research Program, and overall supervised the experiments, presentation of results, design of figures, and writing the manuscript.

\section{Acknowledgements}

The authors thank Dr Sjoerd Joustra for sharing unpublished data on a family with the same gene variant, Dr Dmitry Rodionov for his assistance with the homology modeling, Dr Tanya Silander for her help with preparing some of the figures, and Dr Stephen Butler for assistance in specimen collection.

\section{References}

Cook DM, Ezzat S, Katznelson L, Kleinberg DL, Laws ER Jr, Nippoldt TB, Swearingen B, Vance ML \& Force AAGT 2004 AACE Medical Guidelines for Clinical Practice for the diagnosis and treatment of acromegaly. Endocrine Practice 10 213-225. (doi:10.4158/EP.10.3.213)

Ezzat S, Asa SL, Couldwell WT, Barr CE, Dodge WE, Vance ML \& McCutcheon IE 2004 The prevalence of pituitary adenomas: a systematic review. Cancer 101 613-619. (doi:10.1002/cncr.20412)

Faucz FR, Horvath A, Rothenbuhler A, Almeida MQ, Libe R, Raffin-Sanson M-L, Bertherat J, Carraro DM, Soares FA, Molina Gde et al. 2011 Phosphodiesterase 11A (PDE11A) genetic variants may increase susceptibility to prostatic cancer. Journal of Clinical Endocrinology and Metabolism 96 E135-E140. (doi:10.1210/jc.2010-1655)

Frattini A, Faranda S, Redolfi E, Allavena P \& Vezzoni P 1998 Identification and genomic organization of a gene coding for a new member of the cell adhesion molecule family mapping to Xq25. Gene 214 1-6. (doi:10.1016/S0378-1119(98)00253-4)

Glasker S, Vortmeyer AO, Lafferty AR, Hofman PL, Li J, Weil RJ, Zhuang Z \& Oldfield EH 2011 Hereditary pituitary hyperplasia with infantile gigantism. Journal of Clinical Endocrinology and Metabolism 96 E2078-E2087. (doi:10.1210/jc.2011-1401)

de Herder WW 2012 Familial gigantism. Clinics 67 (Suppl 1) 29-32. (doi:10.6061/clinics/2012(Sup01)06)

Horvath A, Korde L, Greene MH, Libe R, Osorio P, Faucz FR, Raffin-Sanson ML, Tsang KM, Drori-Herishanu L, Patronas Y et al. 2009 Functional phosphodiesterase 11A mutations may modify the risk of familial and bilateral testicular germ cell tumors. Cancer Research 69 5301-5306. (doi:10.1158/0008-5472.CAN-09-0884)

Joustra SD, Schoenmakers N, Persani L, Campi I, Bonomi M, Radetti G, BeckPeccoz P, Zhu H, Davis TM, Sun Y et al. 2013 The IGSF1 deficiency syndrome: characteristics of male and female patients. Journal of Clinical Endocrinology and Metabolism 98 4942-4952. (doi:10.1210/jc.2013-2743)

Joustra SD, Wehkalampi K, Oostdijk W, Biermasz NR, Howard S, Silander T, Bernard DJ, Wit JM, Dunkel L \& Losekoot M 2014 IGSF1 variants in boys with familial delayed puberty. European Journal of Pediatrics [in press] (doi:10.1007/s00431-014-2445-9)

Nakamura A, Bak B, Silander TLR, Lam J, Hotsubo T, Yorifuji T, Ishizu K, Bernard DJ \& Tajima T 2013 Three novel IGSF1 mutations in four Japanese patients With X-linked congenital central hypothyroidism. Journal of Clinical Endocrinology and Metabolism 98 E1682-E1691. (doi:10.1210/jc.2013-1224)

Rejon CA, Ho CC, Wang Y, Zhou X, Bernard DJ \& Hebert TE 2013 Cycloheximide inhibits follicle-stimulating hormone beta subunit transcription by blocking de novo synthesis of the labile activin type II receptor in gonadotrope cells. Cellular Signalling 25 1403-1412. (doi:10.1016/j.cellsig.2013.03.002)

Stratakis CA, Tichomirowa MA, Boikos S, Azevedo MF, Lodish M, Martari M, Verma S, Daly AF, Raygada M, Keil MF et al. 2010 The role of germline AIP, MEN1, PRKAR1A, CDKN1B and CDKN2C mutations in causing 
pituitary adenomas in a large cohort of children, adolescents, and patients with genetic syndromes. Clinical Genetics 78 457-463. (doi:10.1111/j.1399-0004.2010.01406.x)

Sun Y, Bak B, Schoenmakers N, van Trotsenburg ASP, Oostdijk W, Voshol P, Cambridge E, White JK, le Tissier P, Gharavy SN et al. 2012 Lossof-function mutations in IGSF1 cause an X-linked syndrome of central hypothyroidism and testicular enlargement. Nature Genetics $\mathbf{4 4}$ 1375-1381. (doi:10.1038/ng.2453)
Tajima T, Nakamura A \& Ishizu K 2013 A novel mutation of IGSF1 in a Japanese patient of congenital central hypothyroidism without macroorchidism. Endocrine Journal 60 245-249. (doi:10.1507/endocrj.EJ13-0009)

Trivellin G, Daly AF, Faucz FR, Yuan B, Rostomyan L, Larco DO, Schernthaner-Reiter MH, Szarek E, Leal LF, Caberg JH et al. 2014 Gigantism and acromegaly due to Xq26 microduplications and GPR101 mutation. New England Journal of Medicine [in press]. (doi:10.1056/ NEJMoa1408028)

Received in final form 17 November 2014

Accepted 19 November 2014
Published by Bioscientifica Ltd. 